\title{
Correlação entre Trihalometanos e o Desenvolvimento do Câncer de Bexiga
}

doi: https://doi.org/10.32635/2176-9745.RBC.2021v67n4.1588

\author{
Correlation between Trihalomethanes and the Development of Bladder Cancer \\ Correlación entre Trihalometanos y el Desarrollo del Cáncer de Vejiga
}

\author{
Beatriz de Almeida Affornalli'; Nadinne Maria Macetti²; Camila Moraes Marques³; Diancarlos Pereira de Andrade'; Rosiane Guetter \\ Mello ${ }^{5}$
}

\section{RESUMO}

Introdução: Os trihalometanos (THM) constituem um grupo de subprodutos gerados pela desinfecção da água por meio da cloração. Desde a primeira vez em que foram reportados, em 1974, são alvos de estudos que buscam estabelecer uma relação positiva entre a exposição dos humanos a esses compostos e o desenvolvimento de câncer. Objetivo: Revisão da literatura científica disponível sobre a presença de THM na água e sua relação com o desenvolvimento do câncer de bexiga. Método: Levantamento bibliográfico da revisão feito nas bases de dados ScienceDirect e PubMeb. Os descritores utilizados foram "trihalomethane", "disinfection by-products" e "bladder cancer" dos Descritores em Ciências da Saúde (DeCS) da Biblioteca Virtual em Saúde. Os artigos selecionados foram publicados nos últimos cinco anos. Resultados: A amostra final desta revisão foi constituída por 31 artigos, sendo a maioria deles publicados em jornais e revistas sobre meio ambiente. Analisaram-se estudos descritivos, metanálises e outros estudos individuais com delineamento experimental, encontrando uma associação positiva, mas controversa, entre os THM e o câncer, associada a diferentes mecanismos. A relação mais consistente tem sido entre a exposição crônica e o câncer de bexiga. Conclusão: Os estudos reconhecem que existem riscos significativos à saúde relacionados aos THM, no entanto, evidências que esclareçam os mecanismos de ação e o papel que outros fatores de risco possuem, juntamente com os THM, ainda permanecem incertas.

Palavras-chave: Trihalometanos; Subprodutos da Desinfecção; Neoplasias da Bexiga Urinária.

\section{ABSTRACT}

Introduction: The trihalomethanes (THM) are one of the by-products created from the chlorination process, the most applied technique for water disinfection. Since the first time they were reported in 1974, studies attempted to find a positive correlation between human's exposure to THM and cancer. Objective: Review the available scientific literature reported about the presence of THM in drinking water's treatment and its relation with the carcinogenic process of bladder cancer. Method: The present study consists of an integrative literature review. The articles were searched in the ScienceDirect and PubMed databases utilizing the following keywords obtained from the Subject Descriptors in Health Science (Virtual Health Library): "trihalomethanes", "disinfection by-products" and "bladder cancer". Results: In total, 31 articles were selected for this review, most of them published in environmental or toxicological journals. The authors analyzed descriptive studies, meta-analysis and other experimental studies, finding a positive, but controversial relationship between the t THM exposures, specifically the chronic, and the carcinogenic process associated with many pathological mechanisms. Conclusion: The studies recognized the potential risk of the THM exposure in humans, however, more evidence is needed for a better understanding of THM's toxicological aspects and the influence of other health risk factors in the carcinogenicity process. Key words: Trihalomethanes; Disinfection By-Products; Urinary Bladder Neoplasms.

\section{RESUMEN}

Introducción: Los trihalometanos (THM) constituyen un grupo de subproductos generado por la desinfección del agua mediante cloración. Desde la primera notificación en 1974, son objeto de estudios que buscan establecer una relación positiva entre la exposición humana a estos compuestos y el desarrollo de cáncer. Objetivo: Revisión de la literatura científica disponible sobre la presencia de THM en la agua y su relación con el desarrollo del cáncer de vejiga. Método: El estudio bibliográfico de la revisión se realizó em las bases de datos ScienceDirect y PubMeb. Los descriptores utilizados fueron "trihalomethane", "disinfection byproducts" e "bladder cancer" - de Descriptores de Ciencias de la Salud (DeCS) de la Biblioteca Virtual en Salud. Los artículos seleccionados han sido publicados en los últimos 5 años. Resultados: La muestra final de esta revisión consistió en 31 artículos, la mayoría publicados en periódicos y revistas ambientales. Se analizaron estudios descriptivos, metaanálisis y otros estudios individuales con diseńo experimental, encontrando una asociación positiva, pero controvertida, entre los THM y el cáncer asociado con diferentes mecanismos. La relación más consistente ha sido entre la exposición crónica y el cáncer de vejiga. Conclusión: Los estudios reconocen que existen riesgos significativos para la salud relacionados con los THM, sin embargo, las pruebas que aclaran los mecanismos de acción y el papel que otros factores de riesgo tienen, junto con los THM, siguen siendo inciertos. Palabras clave: Trihalometanos; Subproductos de la Desinfección; Neoplasias de la Vejiga Urinaria.

\footnotetext{
1,2,3,5Faculdades Pequeno Príncipe (FPP). Curitiba (PR), Brasil. E-mails: affornalli@gmail.com; nadinnemaria@hotmail.com; camilam14@gmail.com; rosiane.mello@fpp.edu.br. Orcid iD: https://orcid.org/0000-0003-3813-7160; Orcid iD: https://orcid.org/0000-0003-4045-5010; Orcid iD: https://orcid.org/00000001-5121-922X; Orcid iD: https://orcid.org/0000-0002-0612-3955

${ }^{4}$ Instituto de Pesquisa Pelé Pequeno Príncipe (IPPP). Curitiba (PR), Brasil. E-mail: diancarlospa@gmail.com. Orcid iD: https://orcid.org/0000-0003-0880-898X

Endereço para correspondência: Beatriz de Almeida Affornalli. Avenida Iguaçu, 333 - Rebouças. Curitiba (PR), Brasil. CEP 80230-020. E-mail: affornalli@gmail.com
} 


\section{INTRODUÇÃO}

A baixa qualidade da água é um importante problema de saúde humana enfrentada pelas sociedades em razáo da possibilidade de disseminar doenças que podem afetar populaçôes em escala epidêmica ${ }^{1}$. Várias tecnologias de tratamento de água foram desenvolvidas ao longo dos anos para resolver essa questão sanitária - a desinfecção por cloro foi uma delas ${ }^{1}$.

A cloração é o método de desinfecção da água mais utilizado em razáo da simplicidade, do baixo custo e da eficácia. Quando combinados com a filtração, os sistemas de cloração fornecem notáveis reduçôes nas doenças transmitidas pela água, de modo que os surtos de doenças gastrointestinais transmissíveis desaparecem quando esses processos operam conforme projetado ${ }^{2}$. No entanto, o cloro utilizado na desinfecção reage com a matéria orgânica e inorgânica da água formando os chamados subprodutos de desinfecção (DBP $)^{3}$.

A primeira classe dos DBP, reportada em 1974, foi a dos trihalometanos (THM). Desde então, mais de 700 DBP foram identificados, sendo os principais: ácidos haloacéticos (HAA), haloacetonitrilos (HAN) e os THM ${ }^{4}$. A natureza e a concentração dos DBP formados na água potável dependem das condiçôes de desinfecção e da composiçáo da água da fonte ${ }^{5}$. A diversidade de DBP encontrados na água ocorre porque a matéria orgânica natural reage com os agentes químicos empregados nos processos de desinfecção dando origem a uma mistura complexa de compostos orgânicos, caracterizados por diferentes pesos moleculares e funcionalidades químicas. Portanto, a composição desses subprodutos da desinfecção varia de acordo com a composição da água, $\mathrm{pH}$ e outros fatores como estação e clima ${ }^{5}$. Os THM, por sua vez, constituem a classe mais comum e dominante de DBP, contribuindo com 10-20\% na composição da água clorada ${ }^{6}$. Por sua alta prevalência e concentração, são os compostos mais estudados ${ }^{7}$.

Os relatos na literatura estabelecem uma relação íntima entre a exposição aos THM, mais especificamente a crônica, e seus efeitos adversos, uma vez que, após a absorção, esses elementos tendem à bioacumulação no organismo, causando citotoxicidade, genotoxicidade e mutagenicidade, resultando assim em efeitos cancerígenos. Por isso, são frequentemente relatados na literatura como potenciais carcinogênicos, possuindo uma estreita relação com o câncer de bexiga e eventualmente, mas com uma prevalência menor, com câncer de cólon e de reto ${ }^{7,8}$.

A associação mais consistente tem sido com o câncer de bexiga, uma das neoplasias mais comuns do trato urinário. Com estimativas de cerca de 60 mil novos casos por ano, o câncer de bexiga é um dos mais prevalentes entre os homens americanos - depois do câncer de pele, próstata, cólon e pulmão ${ }^{9,10}$. No Brasil, o número de casos novos de câncer de bexiga estimados para cada ano do triênio 2020-2022 será de 7.590 casos em homens e de 3.050 em mulheres ${ }^{11}$.

Dada a sua ocorrência generalizada, os potenciais impactos à saúde humana e a toxicidade, associados à exposiçáo aos THM, são de particular interesse em virtude do seu potencial carcinogênico. Compreender as implicações para a saúde pública dessa questão emergente é crucial para o desenvolvimento de planos de segurança hídrica mais eficazes ${ }^{12}$. O objetivo principal deste trabalho é revisar a literatura científica disponível sobre a presença de THM na água e sua relaçáo com o desenvolvimento do câncer de bexiga.

\section{MÉTODO}

O estudo é uma revisão integrativa realizada por meio de uma busca nas seguintes bases de dados ScienceDirect e PubMed. A primeira etapa da pesquisa foi a elaboração da pergunta norteadora: "Qual a correlação dos THM com o desenvolvimento do câncer de bexiga?". Para a segunda etapa da pesquisa, caracterizada pela busca e seleçáo dos estudos, foram empregados os seguintes Descritores em Ciências da Saúde (DeCS): "trihalomethane" AND "disinfection by-products" AND "bladder cancer", e aplicado o filtro de publicaçóes dos últimos cinco anos. Foram encontrados 192 artigos, teses, dissertaçôes, capítulos de livros, estudos experimentais, metanálises, bem como outras revisões, sendo apenas um deles duplicado. Dos 191 estudos restantes, 43 foram selecionados a partir da leitura do resumo. A partir da leitura completa e aplicando os seguintes critérios de exclusão: texto completo não encontrado; artigos que abordavam a carcinogênese de outras neoplasias, senão a de bexiga; e aqueles publicados em outro idioma que não fossem em português ou inglês, restaram 19 artigos para a revisão de literatura.

Ao final da busca e seleção dos estudos, foram incluídos outros nove artigos, respeitando os critérios de inclusão estabelecidos: últimos cinco anos (2015-2020), texto completo e artigos nos idiomas inglês ou português. Dessa forma, foram utilizados 28 artigos, no total, para a terceira etapa da revisão - caracterizada pela coleta de dados contidos nos estudos (Figura 2). Para a quarta e quinta etapas deste estudo, analisou-se, de forma crítica, o conteúdo dos artigos incluídos, para que, a partir dessa análise, fosse realizada a síntese e discussão dos resultados. Por fim, a sexta e a última etapas desta pesquisa são caracterizadas pela apresentação da revisão integrativa completa. As etapas da revisão integrativa estão ilustradas na Figura 1. 


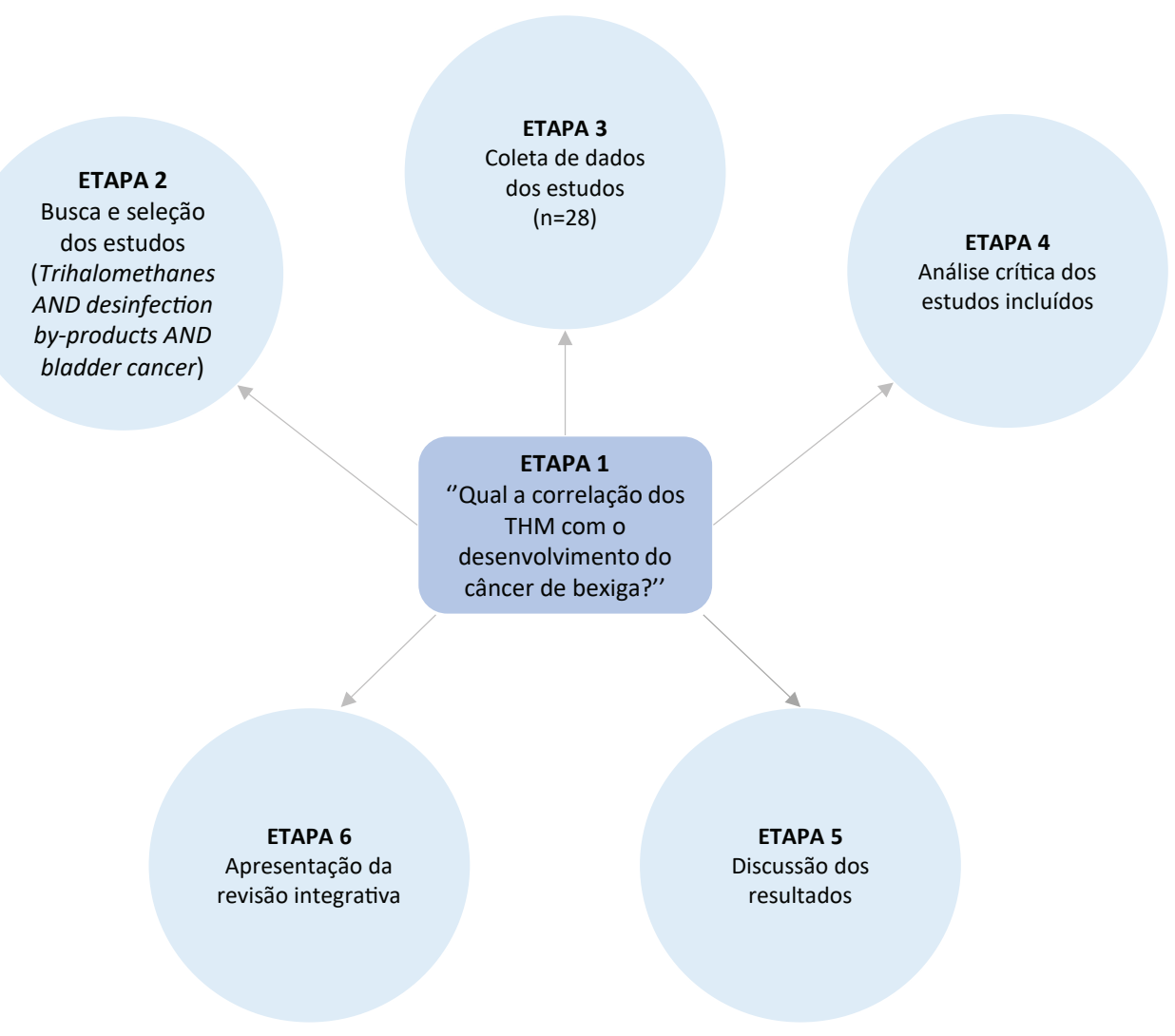

Figura 1. Ełapas da revisão integrativa Fonte: Adaptado de Mendes et al. ${ }^{13}$.

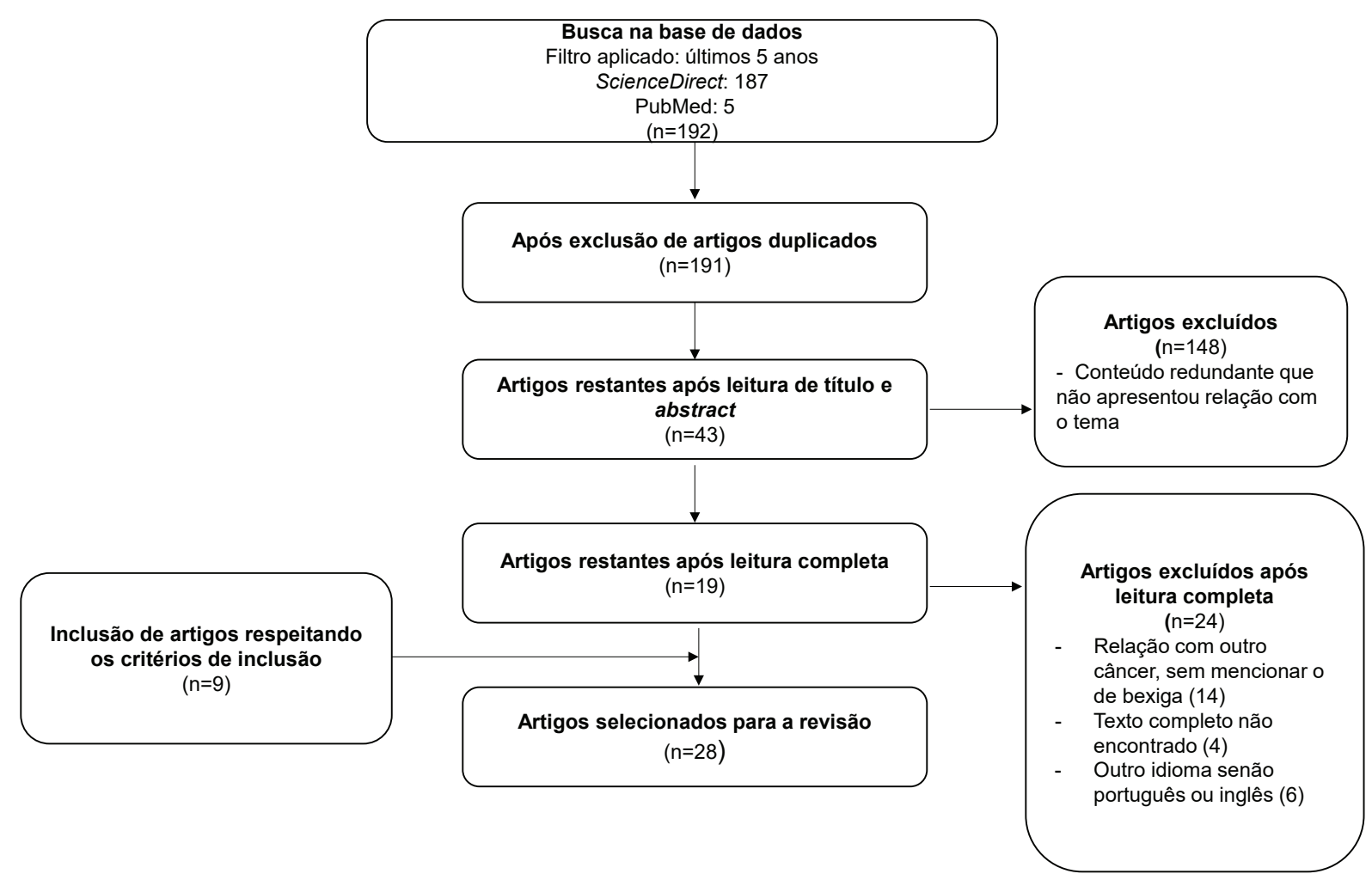

Figura 2. Fluxograma com as etapas da pesquisa 


\section{RESULTADOS}

A amostra final desta revisão foi constituída por 28 artigos científicos. Estes foram publicados em jornais e revistas sobre meio ambiente de vários lugares do mundo, incluindo, em maior número, Estados Unidos da América, China e Espanha seguido de Austrália, Canadá, Coreia do Sul, Portugal, Índia, Turquia, África do Sul e França. Após a análise crítica dos artigos incluídos no estudo, os principais resultados - apresentados por ordem de ano de publicação encontram-se no Quadro 1.

Quadro 1. Resumo dos efeitos dos THM e DBP no desenvolvimento do câncer de bexiga

\begin{tabular}{|c|c|c|c|}
\hline Artigo & Método & Autores/Ano & Resultados \\
\hline $\begin{array}{l}\text { Epidemiology of bladder } \\
\text { cancer }\end{array}$ & $\begin{array}{l}\text { Revisão extraída de capítulo do } \\
\text { livro "Bladder cancer, an issue } \\
\text { of hematology/oncology clinics } \\
\text { of North America" }\end{array}$ & Malats e Real, 2015 & $\begin{array}{l}\text { Foi encontrada uma associação positiva entre os subprodutos da cloração } \\
\text { da água (OR: 1,24; } 95 \% \text { Cl, 1,09-1,41) e o câncer de bexiga urotelial. A } \\
\text { prevalência é em homens, expostos a uma média de } 1 \text { ug/L (partículas por } \\
\text { bilhão) de THM. Nenhuma associação foi relatada com as mulheres - } 0 \\
\text { autor sugere que a divergência desses resultados pode ser em decorrência } \\
\text { das diferenças geográficas dos países Europeus: França, Finlândia e } \\
\text { Espanha; e dos países da América do Norte: Estados Unidos e Canadá }\end{array}$ \\
\hline $\begin{array}{l}\text { Overview of disinfection } \\
\text { by-products and } \\
\text { Associated Health Effects }\end{array}$ & Revisão de literatura & $\begin{array}{l}\text { Villanueva et al., } \\
2015\end{array}$ & $\begin{array}{l}\text { Em humanos, houve uma relação positiva com o câncer de bexiga } \\
\text { em decorrência da exposição a uma concentração de THM > 49ug/L } \\
\text { juntamente com a presença de polimorfismo da CYP2E1 (OR: 2,0; } 95 \% \mathrm{Cl} \\
(1,1-3,9) \text {. Com relação aos THM bromados, o metabolismo é alterado por } \\
\text { meio da GSTT1 (OR: 1,8; } 95 \% \text { Cl 1,1-3,1) que gera moléculas de carbonil } \\
\text { capazes de reagir a gerar danos ao DNA observados em estudos in vitro }\end{array}$ \\
\hline $\begin{array}{l}\text { Assessing the human } \\
\text { health impacts of } \\
\text { exposure to disinfection } \\
\text { by-products - A critical } \\
\text { review of concepts and } \\
\text { methods }\end{array}$ & Revisão de literatura & Grellier et al., 2015 & $\begin{array}{l}\text { Os DBP não regulamentados apresentam um risco carcinogênico maior do } \\
\text { que os THM e HAA. Portanto, conforme mais pesquisas forem surgindo a } \\
\text { respeito dos DBP não regulamentados, a relevância dos THM como agentes } \\
\text { carcinogênicos vai diminuindo. No entanto, reforçam a associação positiva } \\
\text { entre a exposição aos THM e o câncer de bexiga em homens, ao passo que } \\
\text { não se encontram evidências de que outros DBP estejam relacionados a } \\
\text { outros cânceres }\end{array}$ \\
\hline Mutagens & $\begin{array}{l}\text { Revisão publicada em capítulo } \\
\text { do livro "Encyclopedia of Food } \\
\text { and Health" }\end{array}$ & Schrader, 2003 & $\begin{array}{l}\text { A desinfecção com processos de cloração produz mutagênicos de compostos } \\
\text { clorados - sendo o 3-cloro-4-(diclorometil)-5-hidroxi-2-(5H)-furonona } 0 \\
\text { mais potente. Os THM bromados foram os compostos mais relacionados } \\
\text { com os processos de mutação }\end{array}$ \\
\hline $\begin{array}{l}\text { Blood trihalomethane } \\
\text { levels and the risk of total } \\
\text { cancer mortality in US } \\
\text { adults }\end{array}$ & $\begin{array}{l}933 \text { adultos sem histórico de } \\
\text { câncer foram avaliados de } \\
\text { acordo com as concentrações } \\
\text { de THM no sangue em } \\
\text { paralelo com a análise das } \\
\text { causas de mortes listadas no } \\
\text { "International Classification of } \\
\text { Disease 10the Revision" }\end{array}$ & Min e Min, 2016 & $\begin{array}{l}\text { Houve uma relação positiva mais prevalente em adultos entre } 40-59 \text { anos } \\
\text { com níveis séricos elevados de dibromoclorometano, bromofórmio e THM } \\
\text { bromados no geral. } 0 \text { risco de mortalidade por neoplasias nesses pacientes } \\
\text { foi, aproximadamente, } 4 \text { vezes maior do que aqueles que não foram } \\
\text { expostos a essas substâncias ou que tiveram um grau de exposição menor }\end{array}$ \\
\hline $\begin{array}{l}\text { Occurrence, origin, and } \\
\text { toxicity of disinfection } \\
\text { byproducts in chlorinated } \\
\text { swimming pools: an } \\
\text { overview }\end{array}$ & Revisão de literatura & Manasfi et al., 2017 & $\begin{array}{l}\text { Verificou-se um aumento no risco de câncer de bexiga entre os } \\
\text { participantes expostos aos THM via natação OR: 1,5 (95\% Cl 1,18- } \\
\text { 2,09) e ducha/banho OR: 1,83 ( } 95 \% \text { Cl 1,17-2,87). A via dérmica seria } \\
\text { responsável por 94,2\% da exposição total do THM para os nadadores }\end{array}$ \\
\hline $\begin{array}{l}\text { Occurrence and formation } \\
\text { of disinfection by-products } \\
\text { in the swimming pool } \\
\text { environment: a critical } \\
\text { review }\end{array}$ & Revisão de literatura & Carter e Joll, 2017 & $\begin{array}{l}\text { A inalação tem sido vista como a principal via causadora de } \\
\text { mutagenicidade, sendo o risco de câncer até três vezes maior do que por } \\
\text { ingestão ou absorção dérmica. Por causa da maior inalação em relação à } \\
\text { ingestão e à maior concentração de DBP em piscinas em relação à água } \\
\text { de enchimento, a regulamentação existente pode não ser suficiente para a } \\
\text { avaliação do risco à saúde associado aos DBP em águas de piscinas }\end{array}$ \\
\hline
\end{tabular}


Quadro 1. continuação

\begin{tabular}{|c|c|c|c|}
\hline Artigo & Método & Autores/Ano & Resultados \\
\hline $\begin{array}{l}\text { Disinfection byproduct } \\
\text { regulatory compliance } \\
\text { surrogates and bromide- } \\
\text { associated risk }\end{array}$ & Estudo observacional transversal & Kolb et al., 2017 & $\begin{array}{l}0 \text { estudo indica que a regulamentação dos THM, definida com base nos } \\
\text { valores de soma da classe TTHM, não captura adequadamente o risco pelo } \\
\text { fato de espécies diferentes possuírem riscos diferentes }\end{array}$ \\
\hline $\begin{array}{l}\text { Gene expression changes } \\
\text { in blood RNA after } \\
\text { swimming in a chlorinated } \\
\text { pool }\end{array}$ & $\begin{array}{l}\text { Os voluntários nadaram por } 40 \\
\text { minutos na piscina. Amostras } \\
\text { de sangue foram coletadas e } \\
4 \text { tipos dos THM (clorofórmio, } \\
\text { bromodiclorometano, } \\
\text { dibromoclorometano } \\
\text { e bromofórmio) foram } \\
\text { mensurados no ar exalado } \\
\text { depois de nadarem. Para } \\
\text { avaliar a intensidade do } \\
\text { exercício físico, mensuraram-se } \\
\text { equivalentes metabólicos, ao } \\
\text { passo que, para avaliação de } \\
\text { expressão do gene, foi utilizado } \\
\text { IlluminaHumanHT-12V3. } \\
\text { Modelos lineares e mistos foram } \\
\text { utilizados para identificar a } \\
\text { relação entre mudanças na } \\
\text { expressão gênica e exposição } \\
\text { ao THM }\end{array}$ & Salas et al., 2017 & $\begin{array}{l}\text { Houve uma mudança significativa na expressão gênica a curto prazo } \\
\text { dos voluntários - medida a partir do aumento dos THM exalados e } \\
\text { quantificação da taxa metabólica após nadarem em piscinas tratadas com } \\
\text { cloro. Apesar disso, o estudo afirma não conseguir distinguir se a mudança } \\
\text { ocorrida é, de fato, relacionada à exposição aos DBP }\end{array}$ \\
\hline $\begin{array}{l}\text { Bladder cancer and } \\
\text { water disinfection } \\
\text { by-product exposures } \\
\text { through multiple routes: } \\
\text { a population-based } \\
\text { case-control study (New } \\
\text { England, USA) }\end{array}$ & $\begin{array}{l}\text { Estudo do tipo caso-controle } \\
\text { na Inglaterra, sendo } \mathrm{n}=1.213 \\
\text { casos e } \mathrm{n}=1.418 \text { controle. } 0 \\
\text { estudo estimou a exposição aos } \\
\text { THM ao longo da vida por meio } \\
\text { das seguintes rotas: ingestão, } \\
\text { banho e horas de uso de } \\
\text { piscinas. Por fim, calcularam-se } \\
\text { as razões de possibilidades, } \\
\text { usou-se intervalo de confiança } \\
\text { de } 95 \% \text {, considerando } \\
\text { regressão logística não } \\
\text { condicional para confundidores } \\
\text { nos resultados }\end{array}$ & $\begin{array}{l}\text { Beane Freeman et } \\
\text { al., } 2017\end{array}$ & $\begin{array}{l}\text { Encontraram uma associação razoável entre câncer de bexiga e a ingestão } \\
\text { média diária e exposição cumulativa de THM nos 5\% com a maior } \\
\text { exposição - especialmente naquelas concentrações acima de } 45 \mathrm{ug} / \mathrm{L} \text {. Este } \\
\text { estudo também evidenciou uma relação positiva semelhante tanto em } \\
\text { homens quanto em mulheres, diferente de outros estudos que relatam } \\
\text { evidências mais fortes em homens. Não foi encontrada relação positiva em } \\
\text { horas de uso de piscinas }\end{array}$ \\
\hline $\begin{array}{l}\text { Multi-route - Multi- } \\
\text { pathway exposure to } \\
\text { trihalomethanes and } \\
\text { associated cumulative } \\
\text { health risks with response } \\
\text { and dose addition }\end{array}$ & $\begin{array}{l}\text { Estudo observacional } \\
\text { longitudinal que estimou os } \\
\text { riscos cumulativos da exposição } \\
\text { aos THM por múltiplas vias por } \\
\text { meio de métodos de resposta e } \\
\text { adição de dose }\end{array}$ & $\begin{array}{l}\text { Genisoglu et al., } \\
2019\end{array}$ & $\begin{array}{l}0 \text { risco carcinogênico dos THM relacionados a cada via de exposição foi } \\
\text { estimado neste estudo. Os valores dos riscos cumulativos foram divididos } \\
\text { em } 4 \text { categorias: sem risco (zona segura), zona de risco aceitável, zona } \\
\text { de risco de baixa prioridade e risco inaceitável (alta prioridade). Foram } \\
\text { encontrados valores que iam da zona segura até às de baixa prioridade } \\
\text { para as vias de ingestão e inalação, enquanto os valores foram estimados } \\
\text { em zona segura para a exposição cutânea }\end{array}$ \\
\hline $\begin{array}{l}\text { Genotoxicity of } \\
\text { disinfection byproducts } \\
\text { and disinfected waters: a } \\
\text { review of recent literature }\end{array}$ & Revisão de literatura & $\begin{array}{l}\text { Cortés e Marcos, } \\
2018\end{array}$ & $\begin{array}{l}\text { THM deram resultados positivos para indução de quebras no DNA a partir } \\
\text { de ensaio cometa. No entanto, o teste detecta danos que geralmente são } \\
\text { reparados a curto prazo pelas células, assim dados de genotoxicidade mais } \\
\text { relevantes para mutações persistentes são necessários. } 0 \text { estudo também } \\
\text { menciona que polimorfismos em algumas enzimas (GSTTI, GSTZ1 e } \\
\text { CYP2E19) modificaram o risco de câncer de bexiga associado ao DBP }\end{array}$ \\
\hline
\end{tabular}


Quadro 1. continuação

\begin{tabular}{|c|c|c|c|}
\hline Artigo & Método & Autores/Ano & Resultados \\
\hline $\begin{array}{l}\text { Blood transcriptional and } \\
\text { microRNA responses to } \\
\text { short-term exposure to } \\
\text { disinfection by-products in } \\
\text { a swimming pool }\end{array}$ & $\begin{array}{l}\text { Um estudo observacional } \\
\text { longitudinal avaliou a } \\
\text { expressão gênica de todo o } \\
\text { genoma e o microRNA de } \\
\text { amostras de sangue coletadas } \\
\text { de } 43 \text { voluntários antes e } 2 \mathrm{~h} \\
\text { após } 40 \text { minutos de natação em } \\
\text { uma piscina clorada }\end{array}$ & $\begin{array}{l}\text { Espín-Pérez et al., } \\
2018\end{array}$ & $\begin{array}{l}\text { Um total de } 1.778 \text { transcrições foram significativamente associadas a } \\
\text { exposições aos THM. Nove genes expressos podem estar ligados ao câncer } \\
\text { de bexiga, pois estão envolvidos em vias relacionadas aos processos de } \\
\text { câncer. Assim, foi visto que a exposição a curto prazo aos DBP, por meio da } \\
\text { natação em piscinas, pode ser indicativa de risco aumentado de câncer de } \\
\text { bexiga ( } p=0,227)\end{array}$ \\
\hline $\begin{array}{l}\text { Drinking Water } \\
\text { Disinfection Byproducts } \\
\text { (DBPs) and human health } \\
\text { effects: multidisciplinary } \\
\text { challenges and } \\
\text { opportunities }\end{array}$ & Revisão de literatura & Li e Mitch, 2018 & $\begin{array}{l}0 \text { estudo questiona se a regulamentação e as pesquisas estão direcionadas } \\
\text { aos compostos certos, visto que os THM e os HAA correspondem a apenas } \\
10 \% \text { do halogênio orgânico total presente nas águas cloradas. Resultados } \\
\text { indicam que classes de DBP não reguladas são ordens de magnitude mais } \\
\text { citotóxicas e genotóxicas do que as reguladas. Mesmo que os fatores de } \\
\text { toxicidade tenham sido identificados, devem ser incorporados a estudos } \\
\text { retrospectivos de epidemiologia do câncer, avaliando as concentrações nas } \\
\text { décadas anteriores, bem como suas variações espaço-temporais }\end{array}$ \\
\hline $\begin{array}{l}\text { Heterogeneity in the } \\
\text { relationship between } \\
\text { disinfection by-products } \\
\text { in drinking water and } \\
\text { cancer: a systematic } \\
\text { review }\end{array}$ & Revisão sistemática & $\begin{array}{l}\text { Benmarhnia et al., } \\
2018\end{array}$ & $\begin{array}{l}\text { Reforça a relação entre a CYP2El no metabolismo do clorofórmio, bem } \\
\text { como das glutationas no metabolismo dos THM bromados e os processos } \\
\text { de carcinogênese. } 0 \text { papel dessas enzimas pode ser fundamental para } \\
\text { entender o motivo pelo qual o câncer de bexiga relacionado aos THM é } \\
\text { mais prevalente em homens - uma vez que, nestes últimos, possuem uma } \\
\text { atividade maior. No entanto, o estudo conclui que ainda faltam evidências } \\
\text { para considerar não somente as disparidades relacionadas ao sexo, como } \\
\text { também aquelas relacionadas às diferenças sociodemográficas }\end{array}$ \\
\hline $\begin{array}{l}\text { Hazard and mode of } \\
\text { action of disinfection by- } \\
\text { products (DBPs) in water } \\
\text { for human consumption: } \\
\text { evidences and research } \\
\text { priorities }\end{array}$ & Revisão de literatura & Chaves et al., 2019 & $\begin{array}{l}\text { De acordo com a revisão, a evidência de associação entre a exposição a DBP e } \\
\text { o câncer não foi consistente para confirmar que essa associação é causal, pois } \\
\text { a grande maioria dos DBP identificados permanece com atividades biológicas } \\
\text { desconhecidas. Além disso, ressalta-se a importância de análise de DBP } \\
\text { não regulamentados, visto que eles demonstraram ser mais genotóxicos e } \\
\text { citotóxicos do que alguns compostos regulamentados, como os THM }\end{array}$ \\
\hline $\begin{array}{l}\text { Application of biomarkers } \\
\text { in the study of the health } \\
\text { effects of disinfection } \\
\text { by-products }\end{array}$ & Revisão de literatura & Chen et al., 2019 & $\begin{array}{l}0 \text { estudo analisou a aplicação de biomarcadores no estudo dos efeitos } \\
\text { dos DBP na saúde e concluiu que não há um biomarcador específico } \\
\text { que comprove a relação da mistura dos DBP com o desenvolvimento de } \\
\text { problemas de saúde }\end{array}$ \\
\hline $\begin{array}{l}\text { Carcinogenicity of } \\
\text { disinfection byproducts in } \\
\text { humans: epidemiological } \\
\text { studies }\end{array}$ & $\begin{array}{l}\text { Revisão retirada da } \\
\text { "Encyclopedia of Environmental } \\
\text { Health - 2nd edition" }\end{array}$ & Villanueva, 2019 & $\begin{array}{l}\text { Os estudos demonstraram uma evidência positiva em relação ao câncer de } \\
\text { bexiga, somente. No entanto, os dados ainda permanecem controversos } \\
\text { devido às metodologias aplicadas e/ou à quantidade baixa de estudos } \\
\text { que comprovem questões como: exposição a longo prazo, divergência na } \\
\text { prevalência entre homens e mulheres, avaliação de diferentes rotas de } \\
\text { exposição e métodos alternativos à cloração de desinfecção }\end{array}$ \\
\hline $\begin{array}{l}\text { Occurrence of disinfection } \\
\text { by-products in swimming } \\
\text { pools and the estimated } \\
\text { resulting cytotoxicity }\end{array}$ & Revisão de literatura & Carter et al., 2019 & $\begin{array}{l}\text { As águas das piscinas analisadas no estudo continham uma concentração } \\
\text { molar até } 100 \text { vezes mais altas de DBP totais, incluindo THM, em } \\
\text { comparação com as águas de enchimento não tratadas. Verificou-se que } \\
\text { THM, HNM e HAA não contribuem significativamente para a citotoxicidade } \\
\text { crônica estimada }\end{array}$ \\
\hline $\begin{array}{l}\text { National trends of } \\
\text { bladder cancer and } \\
\text { trihalomethanes in } \\
\text { drinking water: a } \\
\text { review and multicountry } \\
\text { ecological study }\end{array}$ & Revisão sistemática de literatura & $\begin{array}{l}\text { Cotruvo e Amato, } \\
2019\end{array}$ & $\begin{array}{l}0 \text { estudo não encontrou uma ligação forte ou consistente entre TTHM e } 0 \\
\text { câncer de bexiga. Ele apoia os achados epidemiológicos de que o risco de } \\
\text { câncer de bexiga pela água potável, se houver, é pequeno e provavelmente } \\
\text { está sobrecarregado por muitos outros fatores de risco maiores }\end{array}$ \\
\hline
\end{tabular}


Quadro 1. continuação

\begin{tabular}{|c|c|c|c|}
\hline Artigo & Método & Autores/Ano & Resultados \\
\hline $\begin{array}{l}\text { Disinfection byproducts } \\
\text { potentially responsible for } \\
\text { the association between } \\
\text { chlorinated drinking water } \\
\text { and bladder cancer: a } \\
\text { review }\end{array}$ & Revisão de literatura & Diana et al., 2019 & $\begin{array}{l}\text { Este estudo comparou estruturas de DBP com } 76 \text { agentes cancerígenos de } \\
\text { bexiga. Os THM e HAA regulamentados são muito menos potentes para } \\
\text { explicar o risco de câncer de bexiga do que as nitrosaminas. No geral, com } \\
\text { base nos dados de genotoxicidade e citotoxicidade, os DBP nitrogenados } \\
\text { são mais tóxicos do que os iodados, que são mais tóxicos do que os } \\
\text { bromados que, por sua vez, são mais tóxicos do que os clorados }\end{array}$ \\
\hline $\begin{array}{l}\text { Trihalomethanes: } \\
\text { concentrations, cancer } \\
\text { risks, and regulations }\end{array}$ & Revisão de literatura & $\begin{array}{l}\text { Cotruvo e Amato, } \\
2019\end{array}$ & $\begin{array}{l}\text { Os dados de tendência nacional (EUA) do câncer de bexiga desde que os } \\
\text { TTHM foram descobertos e regulamentados não refletem uma forte ligação } \\
\text { entre os TTHM e a incidência de câncer de bexiga. } 0 \text { potencial para uma } \\
\text { contribuição mensurável da água potável para o risco de câncer de bexiga } \\
\text { não é óbvio, e a causalidade associada à água potável não foi estabelecida }\end{array}$ \\
\hline $\begin{array}{l}\text { The toxic potentials and } \\
\text { focus of disinfection } \\
\text { byproducts based on the } \\
\text { human embryonic kidney } \\
\text { (HEK293) cell model }\end{array}$ & Estudo experimental in vitro & Chen et al., 2019 & $\begin{array}{l}0 \text { tribromoacetaldeído faz inibiçãa celular em concentraçães baixíssimas. } \\
\text { Apesar de não ser um THM propriamente dito, esse composto tende } \\
\text { a se transformar em THM durante a sua degradação. Em relaçãa ao } \\
\text { metabolismo dos DBP, no geral, verificou-se que o alvo da ação desses } \\
\text { subprodutos foi no metabolismo mitocondrial (produção de ATP), } \\
\text { desidrogenase láctica, bem como na produção de espécies radioativas de } \\
\text { oxigênio }\end{array}$ \\
\hline $\begin{array}{l}\text { Toxicological aspects } \\
\text { of trihalomethanes: a } \\
\text { systematic review }\end{array}$ & Revisão de literatura & de Castro et al., 2019 & $\begin{array}{l}\text { É necessário um entendimento maior sobre potencial risco à saúde, } \\
\text { principalmente pela falta de estudos experimentais aplicados, que muitas } \\
\text { vezes não refletem a realidade da toxicologia. Uma possível explicação } \\
\text { pela qual há diferenças na toxicidade dos THM é de que seus compostos } \\
\text { atuam em sinergismo ou com efeitos toxicológicos aditivos entre eles. Por } \\
\text { fim, outro ponto a se considerar é que a maioria dos estudos levantados } \\
\text { por essa revisão foi feito em ensaios com bactérias, portanto é possível } \\
\text { que não tenha a mesma aplicabilidade para humanos, dada a distância } \\
\text { filogenética }\end{array}$ \\
\hline $\begin{array}{l}\text { The unveiling of a new } \\
\text { risk factor associated with } \\
\text { bladder cancer in Lebanon }\end{array}$ & Estudo caso-controle & Temraz et al., 2019 & $\begin{array}{l}\text { 8,65\% dos casos de câncer de bexiga foram associados à exposição aos } \\
\text { THM. A limitação desse último dado é de que não foi possível distinção } \\
\text { por idade, gênero, localização, fatores socioeconômicos e hábitos de vida. } \\
\text { Por isso, reforçam a necessidade de um estudo que aborde com mais } \\
\text { confiabilidade o papel do tabagismo e da exposição aos THM atuando em } \\
\text { sinergia como fatores de risco para o câncer de bexiga }\end{array}$ \\
\hline $\begin{array}{l}\text { Trihalomethanes in } \\
\text { drinking water and } \\
\text { bladder cancer burden in } \\
\text { the European Union }\end{array}$ & Estudo caso-controle & $\begin{array}{l}\text { Evlampidou et al., } \\
2020\end{array}$ & $\begin{array}{l}\text { A fração atribuída ao risco na população exposta a uma concentração } \\
\text { média de } 11,7 \text { ug/L dos THM na água foi de } 4,9 \% \text {. Matematicamente, isso } \\
\text { representa } 6.561 \text { casos de câncer de bexiga que atingem, todos os anos, } \\
\text { tanto mulheres quanto homens acima dos } 20 \text { anos de idade }\end{array}$ \\
\hline $\begin{array}{l}\text { Analysis of cumulative } \\
\text { cancer risk associated with } \\
\text { disinfection byproducts } \\
\text { in United States drinking } \\
\text { water }\end{array}$ & $\begin{array}{l}\text { Estudo observacional } \\
\text { longitudinal que utilizou } \\
\text { o conjunto de dados } \\
\text { do monitoramento de } \\
\text { contaminantes não } \\
\text { regulamentados da USEPA dos } \\
\text { EUA (UCMR4) e os dados de } \\
\text { ocorrência de THM e HAA em } \\
\text { mais de } 48 \text { mil comunidades. } \\
\text { A análise dos conjuntos de } \\
\text { dados incluiu } 4 \text { THM regulados } \\
\text { e } 9 \text { HAA. Foram calculados os } \\
\text { coeficientes de risco a partir dos } \\
\text { dados obtidos }\end{array}$ & Evans et al., 2020 & $\begin{array}{l}\text { Calcula-se que cerca de } 6.800 \text { casos por ano e } 828 \text { mil casos ao longo da } \\
\text { vida podem ser por causa da presença de subprodutos de desinfecção } \\
\text { na água potável nos EUA. Os riscos cumulativos de acordo com estudos } \\
\text { epidemiológicos e toxicológicos são significativamente maiores do que } 0 \\
\text { risco considerado aceitável pela USEPA }\end{array}$ \\
\hline
\end{tabular}


Quadro 1. continuação

\begin{tabular}{|l|l|l|l|}
\hline \multicolumn{1}{|c|}{ Artigo } & \multicolumn{1}{|c|}{ Método } & \multicolumn{1}{c|}{ Autores/Ano } & \multicolumn{1}{c|}{ Resultados } \\
\hline $\begin{array}{l}\text { Contemporary issues } \\
\text { on the occurrence and } \\
\text { removal of disinfection } \\
\text { byproducts in drinking } \\
\text { water - a review }\end{array}$ & Revisão de literatura & $\begin{array}{l}\text { Chaukura et al., } \\
2020\end{array}$ & $\begin{array}{l}\text { Apesar dos riscos significativos à saúde, existem lacunas de conhecimento } \\
\text { sobre os impactos adversos dos DBP à saúde. Os dados sobre os } \\
\text { riscos humanos são escassos, e o que está disponível é limitado pelas } \\
\text { metodologias de pesquisa usadas para obter dados toxicológicos. Assim, } \\
\text { estudos toxicológicos ambientalmente realistas devem ser realizados para } \\
\text { estabelecer os riscos para a saúde pública associados a DBP emergentes } \\
\text { espećíicos e fornecer dados empíricos suficientes para considerar a } \\
\text { regulamentação futura de DBP emergentes }\end{array}$ \\
\hline
\end{tabular}

Legendas: GSTT1 = Glutationa S-transferase theta-1; OR = Odds-ratio; DNA = Ácido desoxirribonucleico; DBP = Subprodutos de desinfecçáo; THM = Trihalometanos; HAA = Ácidos haloacéticos; TTHM = Trihalometanos totais; GSTZ1 = Glutationa S-transferase zeta 1; CYP2E19 = Citocromo P450 2E19; CYP2E1 = Citocromo P450 2E1; ATP = Adenosina trifosfato; UCMR4 = The Fourth Unregulated Contaminant Monitoring Rule; USEPA = United States Environmental Protection Agency; EUA = Estados Unidos da América; $\mathrm{CI}=$ Cloro.

\section{DISCUSSÃO}

\section{SURGIMENTO DOS TRIHALOMETANOS}

O principal precursor dos THM é a molécula de metano, em que três átomos de hidrogênio são trocados por três átomos de halogênio. Os halogênios podem ser cloro, bromo, iodo, ou suas combinaçóes - dando origem aos quatro principais subtipos dos THM: clorofórmio, bromodiclorometano, dibromoclometano e bromofórmio ${ }^{14}$. Um valor conhecido como trihalometanos totais (TTHM) é frequentemente apresentado e refere-se à soma dos quatro THM individuais mais frequentemente encontrados na água tratada ${ }^{15,16}$.

\section{VIAS DE EXPOSIÇÃO}

As três principais vias de exposição humana aos THM são ingestão oral, inalação e contato dérmico. Assim sendo, os seres humanos são expostos aos THM principalmente por meio da ingestáo direta de água da torneira, por inalação de compostos voláteis e absorção dérmica durante o banho e natação em piscinas cloradas ${ }^{12,17,18}$. Mais especificamente nas piscinas, há adição contínua de uma ampla gama de desinfetantes, produtos químicos naturais, excreções do corpo humano, produtos farmacêuticos e de cuidados pessoais. Desse modo, o conteúdo total de carbono orgânico é geralmente muito maior do que o detectado em águas potáveis, logo, a propensão à formação dos THM é maior ${ }^{15,19}$.

\section{REguLAMENTAÇÃO}

Em 1998, o nível regulatório permitido para TTHM nos EUA passou de 100 para $80 \mu \mathrm{g} / \mathrm{L}$, como resultado de uma medida alternativa para diminuir o risco excessivo de câncer relacionado à exposição a DBP na água potável, como demonstraram alguns estudos epidemiológicos sendo o câncer de bexiga o resultado mais relevante para se beneficiar dessa regulamentaçáo ${ }^{20}$. Desde a Portaria n. ${ }^{\circ}$
36/199021, o Ministério da Saúde regulamenta como 100 $\mu \mathrm{g} / \mathrm{L}$ o limite máximo de THM totais na água permitidos no Brasil.

\section{THM E CÂNCER DE BEXIGA}

O câncer de bexiga é o nono câncer mais comum em todo o mundo, possui uma incidência anual de aproximadamente $430 \mathrm{mil}$ casos e ocupa o $13^{\circ} \mathrm{em}$ mortalidade anual por câncer ${ }^{22}$. A incidência do câncer de bexiga está muito relacionada com a idade. Cerca de 90\% dos cânceres de bexiga ocorrem acima dos 55 anos. Além disso, os homens têm uma probabilidade duas a quatro vezes maior de desenvolver câncer de bexiga do que as mulheres durante a vida ${ }^{2}$. Uma das hipóteses é o papel que os androgênios e os estrógenos, com os diferentes efeitos fisiológicos que podem variar entre os sexos, exercem no processo de carcinogênese ${ }^{23}$. Particularmente, essa probabilidade ainda dobra em homens caucasianos quando comparados aos homens afrodescendentes.

No geral, a epidemiologia tende a variar de acordo com o país, visto que muitos hábitos culturais podem ser considerados fatores de risco para essa doença principalmente o tabagismo ${ }^{23}$. Outros fatores de risco conclusivos incluem a exposição a aminas aromáticas e hidrocarbonetos policíclicos, diabetes mellitus tipo 2, etnia, transplante renal, sobrepeso, obesidade, vírus do papiloma humano (HPV), infecçôes pelo HIV, exposição ocupacional ao arsênio, entre outros ${ }^{2}$. A suscetibilidade genética também contribui como um importante fator de risco. A evidência mais sólida encontrada é o polimorfismo nulo do glutationa S-transferase $\mathrm{Mu} 1$ $\left(\right.$ GSTM1) ${ }^{23}$. Quanto à exposição aos subprodutos da desinfecção - especialmente a exposição aos THM - as evidências que estabelecem o principal mecanismo de ação envolvido no processo de carcinogênese do câncer de bexiga permanecem incertas ${ }^{23}$.

Em 1991, os THM foram classificados, no geral, como carcinogênicos do grupo 3 e grupo 2B pela International 
Agency for Research on Cancer (IARC). Não havia, portanto, evidências suficientes que comprovassem a relação entre a exposiçáo aos THM e o aumento da mortalidade em decorrência do câncer de bexiga, bem como de outras neoplasias, em humanos ${ }^{24}$. Isso ocorreu principalmente pelas limitaçôes metodológicas que os estudos realizados apresentavam $^{25}$. Entre elas, destaca-se a dificuldade de quantificar a influência que outros fatores de risco - tais como poluição do ar, estilo de vida, nutrição e ocupação - tinham, juntamente com os THM, nos processos de carcinogênese ${ }^{25}$. Apesar disso, novos estudos questionam uma possível mudança nesse cenário, especialmente um deles conduzido por uma metanálise sistemática que demonstra o papel dos THM como fator de risco preponderante no desenvolvimento do câncer de bexiga - predominantemente em adultos do sexo masculino ${ }^{26}$.

É sabido que cada subclasse dos THM parece estar relacionada com um mecanismo de ação diferente, portanto, os efeitos podem ser genotóxicos, mutagênicos e/ou citotóxicos ${ }^{1}$. Uma revisão publicada dez anos depois da classificaçáo estabelecida pela IARC avaliou os efeitos toxicológicos do clorofórmio e demonstrou não haver propriedades mutagênicas ${ }^{27,28}$. Isso significa que pelo menos essa subclasse dos THM altera a integridade celular e pode gerar danos, mas não sucessivamente e insuficientes a ponto de alterarem a sequência de nucleotídeos no $\mathrm{DNA}^{8,29}$. Quando avaliada em ensaios utilizando bactérias e células eucarióticas de roedores, apresentou-se como agentes químicos com potencial citotóxico, envolvendo processos de morte e inativação celular, ao interferir no metabolismo do citocromo P450 2E1 (CYP2E1) ${ }^{1,8}$. Durante essa reação, o fosgênio é gerado como intermediário capaz de reagir com fosfolipídios, ligar-se a proteínas e reduzir a atividade das glutationas ${ }^{8}$. Foi demonstrado em estudo que a exposição aos DBP, no geral, quando associada a polimorfismos da CYP2E1, aumentou o risco para o desenvolvimento do câncer de bexiga ${ }^{8}$.

Um estudo nos Estados Unidos indicou que indivíduos adultos com altos níveis de THM bromados no sangue bromofórmio $(1,2 \mathrm{pg} / \mathrm{mL})$, bromodiclorometano $(4,1 \mathrm{pg} /$ $\mathrm{mL}$ ) - têm um risco quatro vezes maior de desenvolver câncer ${ }^{30,31}$. Em relação aos THM bromados, o mecanismo de ação é mutagênico e está ligado com a disfunção do sistema da glutationa S-transferase, mais especificamente a Theta-1 (GSTT1-1). Como há prejuízo no processo de metabolização, moléculas reativas de carbonil dos THM são geradas com potencial de se ligarem ao DNA em ensaios in vitro ${ }^{8}$. Apesar de as glutationas também serem relatadas como mecanismo de ação da citoxicidade do clorofórmio, os THM bromados têm um potencial de alteração do metabolismo dessas enzimas, por meio da conjugação do gene GSTT1-1, em doses mais baixas ${ }^{31}$. Um estudo experimentado em bactérias Salmonella sp em ensaios de mutaçáo de DNA mitocondrial avaliou o grau de mutagenicidade e citotoxicidade dos THM bromados por meio da análise do gene da GSTT1-1, que se apresentou menos expresso. Nesse experimento, concluiu-se que o bromofórmio e o dibromoclorometano apresentaram um risco tanto mutagênico quanto citotóxico maior se comparado ao bromodiclorometano ${ }^{31}$.

Existem indivíduos mais predispostos a sofrerem alterações na ação das glutationas, visto que possuem polimorfismos genéticos que atuam justamente na formação dessas enzimas. Um estudo na Espanha demonstrou que a associação entre a exposição aos THM e o câncer de bexiga foi mais forte nos indivíduos que possuíam polimorfismos nos genes GSTT1 e GSTZ1, que codificam as enzimas glutationa $S$-transferases, responsáveis pela metabolização de THM bromados. Assim, por esse mecanismo, os THM bromados teriam a capacidade de escapar do metabolismo hepático de primeira passagem e atingir o tecido-alvo no trato urinário, sendo ativados em intermediários mutagênicos ${ }^{30,32}$.

A maioria dos estudos que identificam os mecanismos de ação dos THM envolvidos nos processos de carcinogênese do câncer de bexiga foram desenvolvidos em ensaios com bactérias e fungos - em que os mecanismos se mostram mutagênicos e citotóxicos por meio da aplicabilidade de ensaios que avaliam tanto a deleçáo recombinante in vitro utilizando Saccharomyces RS112, como a avaliação da mutação do DNA mitocondrial em Salmonella. Logo, pode não ter a mesma aplicabilidade para humanos, dada a distância filogenética ${ }^{1}$. Dessa forma, para avaliar melhor os efeitos toxicológicos dos THM relacionados com o câncer de bexiga em humanos, outros parâmetros foram utilizados em estudos epidemiológicos ${ }^{33}$.

Beane Freeman et al. ${ }^{27}$ demonstraram aumento das chances do desenvolvimento do câncer de bexiga em populaçôes expostas a uma concentração de THM média acima de $45 \mu \mathrm{g} / \mathrm{L}$. Dados de seis estudos do tipo caso-controle, por exemplo, demonstraram que o grupo exposto a essas concentraçóes resultou em uma razão de probabilidade (odds-ratio) de $1,4(95 \% \mathrm{Cl}, 1,2-1,7)$ para o desenvolvimento da doença ${ }^{8,34}$.

A toxicidade também varia de acordo com as vias de exposição. Ashley et al..$^{35}$, Leavens et al. ${ }^{36}$ e Lewis et al..$^{37}$ (apud Villanueva ${ }^{8}$ ) verificaram que a dose interna e o tempo de excreçáo dos THM na corrente sanguínea foram maiores nos casos em que essa substância foi inalada ou absorvida via dérmica. No entanto, apesar de essas vias apresentarem um metabolismo mais lento, outro estudo de Beane Freeman et al. ${ }^{27}$ demonstrou que as razóes de probabilidade (odds-ratio) para o desenvolvimento do 
câncer de bexiga foram maiores nas vias de exposição de ingestão cumulativa $(1,45)$ e nas de ingestão média diária $(1,53)$.

A United States Environmental Protection Agency (USEPA) afirmou que os riscos de câncer de bexiga relatados em estudos epidemiológicos podem ser inexistentes em razão da falta de causalidade estabelecida. Os estudos epidemiológicos direcionados aos THM e sua relação com o câncer de bexiga são limitados porque os períodos de latência para o câncer de bexiga não são conhecidos, visto que náo há consenso sobre o tempo de desenvolvimento do câncer de bexiga após a exposição inicial. No entanto, estima-se que varia, em média, de dez a 30 anos ou mais ${ }^{2,38}$. Além disso, os riscos potenciais são provavelmente sobrecarregados por outros fatores de risco em humanos como tabagismo, gênero, raça, idade e outras comorbidades. A maioria dos estudos epidemiológicos analisou somente uma variável - isso é particularmente limitante dada a complexidade da etiologia do câncer de bexiga ${ }^{2,34,39}$.

Portanto, a contribuição mensurável da exposição aos THM na água potável para o risco carcinogênico não é clara ${ }^{2,34,35}$. Além disso, outro ponto importante a se considerar é que a composição da água pelos THM a longo prazo pode variar dependendo de fatores como temperatura e/ou $\mathrm{pH}$, resultando em diferentes contribuintes e/ou outras vias de exposição que podem não ter sido abordadas nos estudos ${ }^{2,34}$.

Os TTHM são regulados há quase 40 anos e representam o subproduto da desinfecção mais prevalente. Por isso, a medição de suas concentrações totais é utilizada em alguns estudos como parâmetro representativo para avaliação da concentraçáo dos DBP como um todo ${ }^{27}$. A implicação dessa quantificação é que permanece obscura a influência que outros DBP, gerados durante o processo de cloração, incluindo os não regulamentados e/ou não definidos, podem exercer nos processos toxicológicos. De acordo com a literatura, os subprodutos náo regulamentados, e, portanto, menos relatados, podem apresentar genotoxicidade e citotoxicidade maiores aos seres humanos ${ }^{26}$. Logo, questiona-se a premissa de que os TTHM sejam os únicos responsáveis pela carcinogenicidade, uma vez que seus efeitos toxicológicos possam ser resultantes do sinergismo com outros DBP potencialmente cancerígenos ${ }^{2,34,40}$.

Embora os riscos potenciais de câncer de bexiga associados à presença de THM na água potável permaneçam questionáveis, estratégias e práticas apropriadas devem ser pensadas para manter a qualidade da água potável, a fim de evitar exposiçōes excessivas desnecessárias ${ }^{2,34}$. O uso de desinfetantes alternativos como ozônio, dióxido de cloro e cloraminas já vem sendo estudado, pois é sabido que a aplicação desses desinfetantes reduz a concentração dos quatro THM regulados ${ }^{41}$. No entanto, o uso desses desinfetantes como estratégia para diminuir o risco ainda é questionável, visto que eles podem formar um novo conjunto de DBP não regulamentados e com maior toxicidade ${ }^{38}$. Inevitavelmente, sempre que um método de desinfecção for aplicado, sua reação gera subproduto, sendo necessária avaliaçáo entre o risco e benefício que apresentam $^{8}$. Desse modo, é necessário adicionar DBP emergentes tóxicos aos padrôes de qualidade da água, o que pode contribuir para alcançar o objetivo de tornar a água potável mais segura ${ }^{38}$. A remoção de precursores de DBP, como a matéria orgânica natural, também é uma estratégia que tem se demonstrado eficaz. Métodos como coagulação, oxidação avançada e ultrafiltração por membrana são os mais comuns, no entanto, ainda são necessários métodos mais eficientes e econômicos ${ }^{38}$.

\section{CONCLUSÃO}

Os processos de carcinogênese relacionados ao câncer de bexiga ocorrem, sobretudo, em decorrência da soma de fatores genéticos, epigenéticos e exposicionais conforme relatado nesta revisão de literatura. Isso dificulta o estabelecimento de apenas um fator de risco como preponderante para o seu desenvolvimento.

Apesar dos riscos significativos à saúde, os impactos dos THM relacionados ao câncer de bexiga permanecem questionáveis. Os dados sobre os riscos humanos são escassos, e o que está disponível é limitado pelas metodologias de pesquisa usadas para obter dados toxicológicos. Não se pode confirmar que essa associação é causal, pois os THM e a grande maioria de outros DBP identificados permanecem com atividades biológicas desconhecidas. É reconhecido, portanto, que muitos estudos ainda devem ser direcionados a fim de confirmar essa relação.

\section{CONTRIBUIÇÕES}

Beatriz de Almeida Affornalli, Nadinne Maria Macetti e Camila Moraes Marques contribuíram substancialmente na concepçáo e/ou planejamento do estudo; na obtençáo, análise e/ou interpretação dos dados; na redaçáo e revisão crítica. Diancarlos Pereira de Andrade e Rosiane Guetter Mello contribuíram na análise e/ou interpretação dos dados; na redaçáo e revisão crítica. Todos os autores aprovaram a versão final a ser publicada.

\section{DECLARAÇÃO DE CONFLITO DE INTERESSES}

Nada a declarar. 


\section{FONTES DE FINANCIAMENTO}

Não há.

\section{REFERÊNCIAS}

1. de Castro Medeiros L, de Alencar FLS, Navoni JA, et al. Toxicological aspects of trihalomethanes: a systematic review. Environ Sci Pollut Res Int. 2019;26(6):5316-32. doi: https://doi.org/10.1007/s11356-018-3949-z

2. Cotruvo JA, Amato H. National trends of bladder cancer and trihalomethanes in drinking water: a review and multicountry ecological study. Dose Response. 2019;17(1):1559325818807781. doi: https://doi. org/10.1177/1559325818807781

3. Espín-Pérez A, Font-Ribera L, van Veldhoven K, et al. Blood transcriptional and microRNA responses to shortterm exposure to disinfection by-products in a swimming pool. Environ Int. 2018;110:42-50. doi: https://doi. org/10.1016/j.envint.2017.10.003

4. Chen Y, Xu T, Yang X, et al. The toxic potentials and focus of disinfection byproducts based on the human embryonic kidney (HEK293) cell model. Sci Total Environ. 2019;664:948-57. doi: https://doi. org/10.1016/j.scitotenv.2019.01.361

5. Diana M, Felipe-Sotelo M, Bond T. Disinfection byproducts potentially responsible for the association between chlorinated drinking water and bladder cancer: a review. Water Res. 2019;162:492-504. doi: https://doi. org/10.1016/j.watres.2019.07.014

6. Salas LA, Font-Ribera L, Bustamante M, et al. Gene expression changes in blood RNA after swimming in a chlorinated pool. J Environ Sci (China). 2017;58:25061. doi: https://doi.org/10.1016/j.jes.2017.05.011

7. Font-Ribera L, Gràcia-Lavedan E, Aragonés N, et al. Long-term exposure to trihalomethanes in drinking water and breast cancer in the Spanish multicase-control study on cancer (MCC-SPAIN). Environ Int. 2018;112:22734. doi: https://doi.org/10.1016/j.envint.2017.12.031

8. Villanueva CM, Cordier S, Font-Ribera L, et al. Overview of disinfection by-products and Associated Health Effects. Curr Environ Health Rep. 2015;2(1):107-15. doi: https://doi.org/10.1007/s40572-014-0032-x

9. Li XF, Mitch WA. Drinking Water Disinfection Byproducts (DBPs) and human health effects: multidisciplinary challenges and opportunities. Environ Sci Technol. 2018;52(4):1681-9. doi: https://doi. org/10.1021/acs.est.7b05440

10. Zhang H, Chang S, Wang L, et al. Estimating and comparing the cancer risks from THMs and low-level arsenic in drinking water based on disability-adjusted life years. Water Res. 2018;145:83-93. doi: https://doi. org/10.1016/j.watres.2018.08.012
11. Instituto Nacional de Câncer José Alencar Gomes da Silva. Estimativa 2020: incidência de câncer no Brasil [Internet]. Rio de Janeiro: INCA; 2019. [acesso 2020 jul 8]. Disponível em:_https://www.inca.gov.br/sites/ ufu.sti.inca.local/files/media/document/estimativa-2020incidencia-de-cancer-no-brasil.pdf

12. Chaves RS, Guerreiro CS, Cardoso VV, et al. Hazard and mode of action of disinfection by-products (DBPs) in water for human consumption: evidences and research priorities. Comp Biochem Physiol C Toxicol Pharmacol. 2019;223:53-61. doi: https://doi.org/10.1016/j. cbpc.2019.05.015

13. Mendes KDS, Pereira Silveira RCC, Galvão CM. Use of the bibliographic reference manager in the selection of primary studies in integrative reviews. Texto Contexto Enferm. 2019;28:1-13. doi: https://doi. org/10.1590/1980-265X-TCE-2017-0204

14. Paixão R, Silva LHBR, Andreola R. A cloração e a formação de trialometanos. Iniciac Cient CESUMAR. 2014;16(2):191-8.

15. Carter RAA, Joll CA. Occurrence and formation of disinfection by-products in the swimming pool environment: a critical review. J Environ Sci. 2017;58:1950. doi: https://doi.org/10.1016/j.jes.2017.06.013

16. Gomes JMM. Influência de parâmetros operacionais na formação de trihalometanos em águas residuais desinfetadas com cloro [dissertação]. Lisboa: Faculdade de Ciências e Tecnologia e a Universidade Nova de Lisboa; 2019.

17. Manasfi T, Coulomb B, Boudenne JL. Occurrence, origin, and toxicity of disinfection byproducts in chlorinated swimming pools: an overview. Int J Hyg Environ Health. 2017;220(3):591-603. doi: https://doi. org/10.1016/j.ijheh.2017.01.005

18. Genisoglu M, Ergi-Kaytmaz C, Sofuoglu SC. Multiroute - Multi-pathway exposure to trihalomethanes and associated cumulative health risks with response and dose addition. J Environ Manage. 2019;233:823-31. doi: https://doi.org/10.1016/j. jenvman.2018.10.009

19. Carter RAA, Allard S, Croué JP, et al. Occurrence of disinfection by-products in swimming pools and the estimated resulting cytotoxicity. Sci Total Environ. 2019;664:851-64. doi: https://doi.org/10.1016/j. scitotenv.2019.01.428

20. Kolb C, Francis RA, VanBriesen JM. Disinfection byproduct regulatory compliance surrogates and bromide-associated risk. J Environ Sci. 2017;58:191-207. doi: https://doi.org/10.1016/j.jes.2017.05.043

21. Ministério da Saúde (BR). Secretaria de Vigilância em Saúde. Vigilância e controle da qualidade da água para consumo humano [Internet]. Brasília, DF: Ministério da Saúde; 2006 [acesso 2020 jul 8]. Disponível em: https:// 
bvsms.saude.gov.br/bvs/publicacoes/vigilancia_controle_ qualidade_agua.pdf

22. Cumberbatch MGK, Jubber I, Black PC, et al. Epidemiology of bladder cancer: a systematic review and contemporary update of risk factors in 2018. Eur Urol. 2018;74(6):784-95. doi: https://doi.org/10.1016/j. eururo.2018.09.001

23. Malats N, Real FX. Epidemiology of bladder cancer. Hematol Oncol Clin North Am. 2015;29(2):177-89. doi: https://doi.org/10.1016/j.hoc.2014.10.001

24. Temraz S, Haibe Y, Charafeddine M, et al. The unveiling of a new risk factor associated with bladder cancer in Lebanon. BMC Urol. 2019;19:16. doi: https://doi. org/10.1186/s12894-019-0445-9

25. Villanueva CM. Carcinogenicity of disinfection byproducts in humans: epidemiological studies. In: Nriagu J, editor. Encyclopedia of environmental health. 2nd ed. Amsterdam (Netherlands): Elsevier; 2019. p. 517-27.

26. Grellier J, Rushton L, Briggs DJ, et al. Assessing the human health impacts of exposure to disinfection by-products - A critical review of concepts and methods. Environ Int. 2015;78:61-81. doi: https://doi. org/10.1016/j.envint.2015.02.003

27. Beane Freeman LE, Cantor KP, Baris D, et al. Bladder cancer and water disinfection by-product exposures through multiple routes: a population-based case-control study (New England, USA). Environ Health Perspect. 2017;125(6):067010. doi: https://doi.org/10.1289/ EHP89

28. Benmarhnia T, Delpla I, Schwarz L, et al. Heterogeneity in the relationship between disinfection by-products in drinking water and cancer: a systematic review. Int J Environ Res Public Health. 2018;15(5):979. doi: https:// doi.org/10.3390/ijerph15050979

29. Schrader TJ. Mutagens. In: Trugo L, Finglas PM, editors. Encyclopedia of food and health [Internet]. 2nd ed. Oxford, UK: Academic Press; 2003. p. 4059-67. doi: https://doi.org/10.1016/B0-12-227055-X/00817-8

30. Chen Z, Yang L, Li Z, et al. Application of biomarkers in the study of the health effects of disinfection by-products. Curr Opin Environ Sci Health. 2019;7:108-16. doi: https://doi.org/10.1016/j.coesh.2019.01.002

31. Min JY, Min KB. Blood trihalomethane levels and the risk of total cancer mortality in US adults. Environ Pollut. 2016;212:90-6. doi: https://doi.org/10.1016/j. envpol.2016.01.047

32. Cortés C, Marcos R. Genotoxicity of disinfection byproducts and disinfected waters: a review of recent literature. Mutat Res Genet Toxicol Environ Mutagen.
2018;831:1-12. doi: https://doi.org/10.1016/j. mrgentox.2018.04.005

33. Chaukura N, Marais SS, Moyo W, et al. Contemporary issues on the occurrence and removal of disinfection byproducts in drinking water - a review. J Environ Chem Eng. 2020;8(2):103659. doi: https://doi.org/10.1016/j. jece.2020.103659

34. Villanueva CM, Cantor KP, Cordier S, et al. Disinfection byproducts and bladder cancer: a pooled analysis. Epidemiology. 2004;15(3):357-67. doi: https://doi. org/10.1097/01.ede.0000121380.02594.fc

35. Ashley DL, Blount BC, Singer PC, et al. Changes in blood trihalomethane concentrations resulting from differences in water quality and water use activities. Arch Environ Occup Health. 2005;60(1):7-15. doi: https:// doi.org/10.3200/AEOH.60.1.7-15

36. Leavens TL, Blount BC, DeMarini DM, et al. Disposition of bromodichloromethane in humans following oral and dermal exposure. Toxicol Sci. 2007;99(2):432-45. doi: https://doi.org/10.1093/toxsci/kfm 190

37. Lewis C, Suffet IH, Ritz B. Estimated effects of disinfection by-products on birth weight in a population served by a single water utility. Am J Epidemiol. 2006;163(1):38-47. doi: https://doi.org/10.1093/aje/ kwj009

38. Cotruvo JA, Amato H. Trihalomethanes: concentrations, cancer risks, and regulations. J Am Water Works Assoc. 2019;111(1):12-20. doi: https://doi.org/10.1002/ awwa. 1210

39. Evlampidou I, Font-Ribera L, Rojas-Rueda D, et al. Trihalomethanes in drinking water and bladder cancer burden in the European Union. Environ Health Perspect. 2020;128(1):17001. doi: https://doi.org/10.1289/ EHP4495

40. Evans S, Campbell C, Naidenko OV. Analysis of cumulative cancer risk associated with disinfection byproducts in United States drinking water. Int J Environ Res Public Health. 2020;17(6):2149. doi: https://doi. org/10.3390/ijerph17062149

41. Tang Y, Long X, Wu M, et al. Bibliometric review of research trends on disinfection by-products in drinking water during 1975-2018. Sep Purif Technol. 2020;241:116741. doi: https://doi.org/10.1016/j. seppur.2020.116741 